
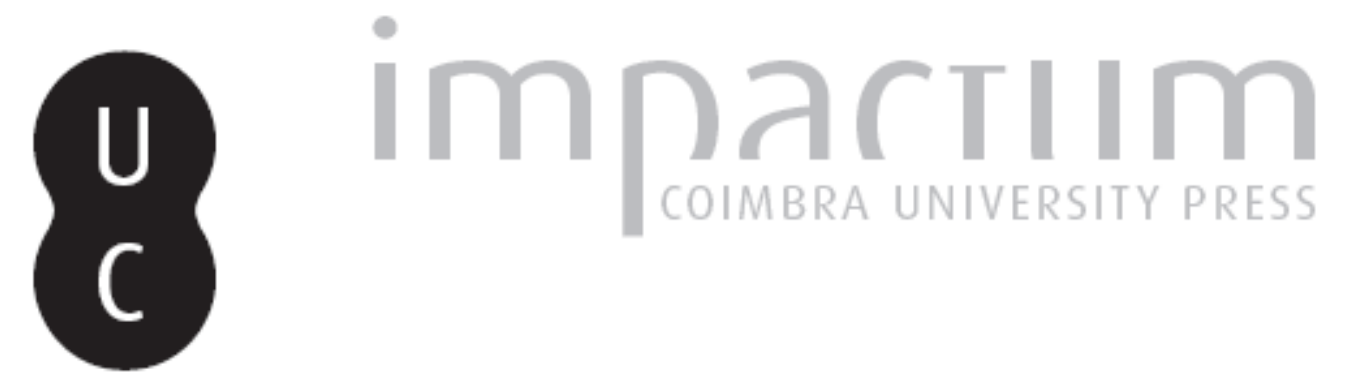

A biblioteca de D. Inácio de Santa Teresa, um bispo jacobeu, entre 1721 e 1751

Autor(es): $\quad$ Alves, Ana Ruas

Publicado por: Centro de História da Sociedade e da Cultura

URL persistente:

URI:http://hdl.handle.net/10316.2/39366

DOI:

DOI:http://dx.doi.org/10.14195/1645-2259_14_8

Accessed : $\quad$ 26-Apr-2023 13:26:37

A navegação consulta e descarregamento dos títulos inseridos nas Bibliotecas Digitais UC Digitalis, UC Pombalina e UC Impactum, pressupõem a aceitação plena e sem reservas dos Termos e Condições de Uso destas Bibliotecas Digitais, disponíveis em https://digitalis.uc.pt/pt-pt/termos.

Conforme exposto nos referidos Termos e Condições de Uso, o descarregamento de títulos de acesso restrito requer uma licença válida de autorização devendo o utilizador aceder ao(s) documento(s) a partir de um endereço de IP da instituição detentora da supramencionada licença.

Ao utilizador é apenas permitido o descarregamento para uso pessoal, pelo que o emprego do(s) título(s) descarregado(s) para outro fim, designadamente comercial, carece de autorização do respetivo autor ou editor da obra.

Na medida em que todas as obras da UC Digitalis se encontram protegidas pelo Código do Direito de Autor e Direitos Conexos e demais legislação aplicável, toda a cópia, parcial ou total, deste documento, nos casos em que é legalmente admitida, deverá conter ou fazer-se acompanhar por este aviso. 


\section{4 \\ 2014}

\section{evista de História da Sociedade e da Cultura}

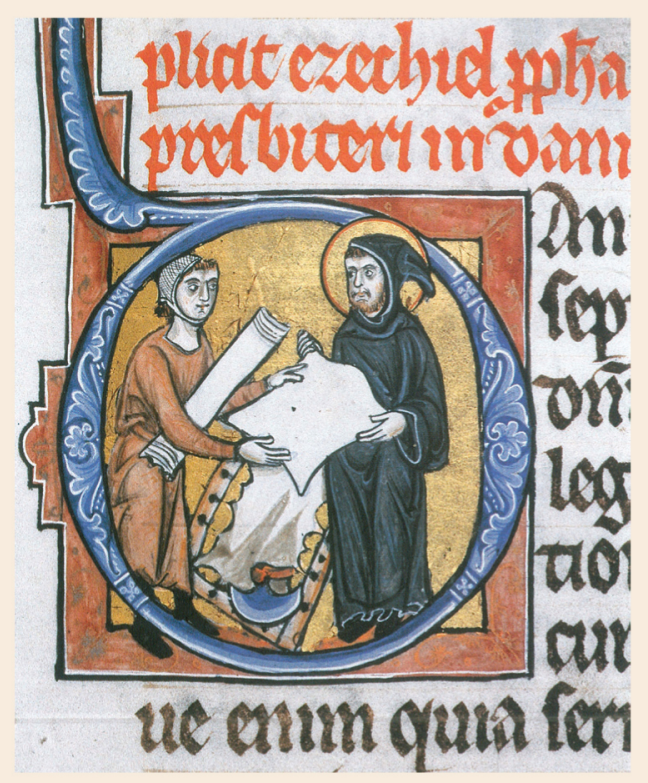

Centro de História da Sociedade e da Cultura Universidade de Coimbra 


\title{
A biblioteca de $D$. Inácio de Santa Teresa, um bispo jacobeu, entre 1721 e 1751
}

\author{
Ana Ruas Alves \\ Centro de Estudos de História Religiosa \\ anaruasalves@gmail.com \\ Texto recebido em/Text submitted on: 12.06 .2014 \\ Texto aprovado em/Text approved on: 02.11.2014
}

Resumo/Abstract:

O estudo tem como objetivo seguir o itinerário literário de D. frei Inácio de Santa Teresa, arcebispo de Goa e mais tarde bispo do Algarve, para a partir dos seus livros traçar o paradigma catequético "os meyos para aquele fim: arrancar vicios, abraçar as virtudes" . $\mathrm{O}$ prelado pertenceu a um elenco de bispos que se salientou pelo rigorismo procurando, pela via de uma vida perfetiva e de oração mental, plantar nas suas áreas de influência o amor a Deus.

This work intends to follow the literary itinerary of D. frei Inácio de Santa Teresa, archbishop of Goa and later bishop of Algarve, in order to draw his catechetic paradigm from the books he owned "the means to that end: tear vices, embrace the virtues"*. The prelate belonged to a group of bishops, who distinguished themselves by their rigourism seeking, through the path of a perfective life and mental prayer, to seed the love of God within their areas of influence.

Palavras chave/Keywords:

Jacobeia; Oração mental; Bispos; Místicos; Parenética; "Livraria".

Jacobeia; Mental prayer; Bishops; Mystics; Parenesis; Library.

* DGARQ - Manuscrito Livraria 1816 - Estado do estado da India obra posthuma d exmo, e Revermo Sr. D. Ignacio de Santa Thereza Arceb de Goa, e depois do Algarve, fl. 60. 


\section{Introdução}

D. frei Inácio nasceu no Porto, tomou o hábito dos cónegos regrantes de Santo Agostinho no mosteiro de Grijó; integrou o Colégio de Santa Cruz e ingressou na Universidade, onde viria a doutorar-se em Teologia em $1711^{1}$. O ambiente em que viveu proporcionou-lhe o convívio com uma elite de intelectuais que defendiam uma vida rigorosa e mística, sob a égide da jacobeia, um movimento renovador da vida religiosa que surgiu no alvor do século XVIII, em Coimbra. O prelado mostrou capacidade de liderança, engenho e eficácia nas suas práticas em Coimbra o que levou frei Gaspar de Encarnação a aconselhar D. João $\mathrm{V}$ a indigitá-lo para a arquidiocese de Goa (6 de Dezembro de 1720, sagrado por Clemente XI a 3 de Fevereiro de 1721$)^{2}$, e para a diocese de Faro (1740, onde entrou a 29 de Novembro de 1741$)^{3}$. Pertenceu a um elenco de bispos que se salientou pelo rigorismo procurando, pela via de uma vida perfetiva e de oração mental, plantar nas suas áreas de influência o amor a Deus. Seguiu métodos e estratégias de disciplinamento que revivesciam os ideais tridentinos. A sua praxis valeu-lhe o antagonismo por parte das congregações e das missões que encontrou no Estado da Índia. De tal forma que foi enredado por dois jesuítas num processo inquisitorial, sob acusação de blasfémia ${ }^{4}$. O rigor adotado aproximava-o de Quesnel e das ideias jansenistas que, contudo, nunca perfilhou. A ambiência política e religiosa de Goa iriam marcar profundamente a sua linha de conduta. Se por um lado, distante da Coroa, o prelado teria que controlar as instituições políticas para assumir o papel que lhe fora destinado pelo rei, na união do Estado com a Igreja, por outro, teria que conviver com um

1 ALVES, Ana Ruas - “O Reyno de Deos”..., cit., AUC - Autos e graus, Vol. 54 IV/I-D, $1,1,54,1 .^{\circ}$ cad., fl. $15 \mathrm{v}$.

2 DGARQ - Manuscritos da Livraria 577 - Vida do Ex.mo e Re.mo Senhor D. Ignacio de Santa Teresa Conego Regular, Arcebispo de Goa e Bispo do do Algarve Escripta por D. Ign. Da B.M., fl. 4v.

3 ALVES, Ana Ruas - "O Reyno de Deos e a sua Justiça”, Dom frei Inácio de Santa Teresa (1682-1751). Dissertação de Doutoramento em História da Época Moderna apresentada na FLUC, 2012, p. 249.

4 ALVES, Ana Ruas - “O Reyno de Deos”..., cit., p. 223-248 e SOUZA, Evergton Sales - Jansénisme et réforme de l'Église dans l'empire portugais 1640 à 1790. Paris: Centre Culturel Calouste Gulbenkian, 2004. 
meio multirreligioso onde o hinduísmo, e o islamismo se entrosavam com o cristianismo, o que para ele era inaceitável.

A cultura elitista barroca é seduzida pelo fascínio da palavra, tornando-se esta fundamental na formação do clero ${ }^{5}$. O poder de decisão que caraterizou o prelado reside na forma como usou a palavra.

Por conseguinte, o objetivo deste estudo é seguir o itinerário da literatura religiosa à disposição de $\mathrm{D}$. frei Inácio de Santa Teresa e indagar até que ponto ela serviu de inspiração catequética e pedagógica durante a sua governação, quer na arquidiocese de Goa quer na diocese de Faro ${ }^{6}$. A partir dos títulos existentes na biblioteca de S. Ignes e de Panchim procurou-se entender o paradigma seguido pelo prelado durante a vida ${ }^{7}$. Crê-se que a sua forte componente intelectual teve um papel fundamental no apostolado, na ação concreta como vigilante na condução das suas ovelhas. A palavra determina a capacidade social e a competência a uma determinada situação como afirma Pierre Bourdieu ${ }^{8}$. Assim, partiu-se para a análise da biblioteca com o intuito de observar até que ponto a reinterpretação dos livros litúrgicos, dos textos catequéticos e da literatura piedosa refletem a renovação espiritual.

Em anexo está o rol de livros existentes na biblioteca privada de D. frei Inácio que se compulsou na Biblioteca Geral da Universidade de Coimbra (Reservados). A partir da análise de alguns títulos referenciados na pastoral do arcebispo chegamos ao possível arquétipo adotado na sua governação.

\section{Os livros e o modelo adotado}

Os princípios jacobeus tinham como propósito observar meticulosamente os preceitos religiosos do catolicismo entre o clero e os seculares, adequar os costumes das populações à ética cristã, aprofundar uma piedade mais

5 MARQUES, João Francisco - "Introdução", in AZEVEDO, Carlos Moreira (dir.) História Religiosa de Portugal, Lisboa: Círculo dos Leitores, 2000, vol. II, p. 9-12.

6 SANTOS, Zulmira - "Literatura Religiosa: Época Moderna" in AZEVEDO, Carlos Moreira (dir.) - Dicionário de História Religiosa. Lisboa: Círculo dos Leitores. 2001, vol. 4, p. 125-130.

7 BGUC - cod. 1524, 293-293v.

8 BOURDIEU, Pierre - Langage et pouvoir symbolique. Paris: Editions du Seuil, 2001, (préface de John B. Thompson), p. 60. 
espiritual e interior do que ritualista. Cabia aos bispos o controlo do seu rebanho. Como é que o prelado concretizava a observância dos preceitos religiosos? Como é que controlava os seus súbditos? De que modo evangelizava a sua diocese? Quais seriam os livros ou manuais onde se inspiraria para adaptar à realidade governativa da arquidiocese de Goa?

A prédica utilizada necessitava de um discurso escorreito e claro para transmitir a palavra de Deus aos fiéis no sentido da salvação das suas almas. A biblioteca de D. frei Inácio de Santa Teresa em Goa era composta por 197 livros (116 na livraria de Panchim e 81 na de S. Inês, tabelas 1 e 2, em anexo) ${ }^{9}$. Do ponto de vista temático, a biblioteca pode dividir-se em direito canónico, teologia, oratória sacra, hagiografias, história, poesia, medicina (a Lus da Medicina de Cabreira) e matemática (os Principia de Newton).

Destaca-se do catálogo: Controversia sobre os Ritos Malabaricos do Padre Brandolini visto o tema ser essencial para o entendimento dos ritos dos gentios, para se proceder à sua conversão e se delinear uma política catequética. No modelo que o prelado adotou há uma evidente tendência para os núcleos religiosos de Espanha ligado aos Carmelos de Granada e de França. Sublinham-se autores como Frei Luís de Granada, cujas obras não estão identificadas, embora tenha sido o difusor do verdadeiro espírito da oração mental ${ }^{10}$; mestre S. João de Ávila; Sor Maria de Jesus Ágreda, María Coronel y Arana; padre António Vieira; padre Bartolomeu de Quental; padre Soares; José Anchieta; S. Francisco de Sales; Santo Agostinho e S. Tomás de Aquino entre outros (embora não se aproximassem da jacobeia).

As hagiografias e as obras de grandes nomes da Igreja terão sido importantes na prática evangelizadora e no controlo da formação e conduta da classe sacerdotal, regular e secular sob a salvaguarda do arcebispo ${ }^{11}$. Os religiosos elencados estavam ligados à devotio moderna cuja atitude pastoral é vincada por uma vivência baseada nas Sagradas Escrituras,

9 BNP - cod. 1524, fl 294 e 294v, códice que indica todos os bens que D. Frei Inácio de Santa Teresa deixou na sua arquidiocese de Goa. BGUC - cod. 1524, 293-293v.

${ }^{10}$ TAVARES, Pedro-Beatas, Inquisidores e Teólogos, Reacção Portuguesa a Miguel de Molinos. Porto: Edição do Centro Inter-Universitário de História da Espiritualidade, 2005, p. 33.

${ }^{11}$ COSTA, Elisa Maria Lopes da - "A Jacobeia achegas para a história de um movimento de reforma espiritual no Portugal setecentista" in Arquipélago, História, 2. a série, XIV-XV (2010-2011), 31-48. 
à defesa da oração mental (meditação e contemplação) e à direção espiritual, ligada à reforma da Península Ibérica ${ }^{12}$. Os referidos autores apelavam constantemente para uma prática afetiva e interior, dominada pela força do espírito e da comunhão da alma com Deus ${ }^{13}$, prática que D. frei Inácio tornou obrigatória na formação do clero.

Dos livros do catálogo não se sabe quais foram comprados ou oferecidos. A diversificação de obras de teologia moral revela a preocupação em preparar o clero como cura de almas. Os títulos mostram as qualidades que o arcebispo procurava para seu paradigma, nomeadamente, nas narrativas de vida dos santos e mártires (tabela 1). Após o Concílio de Trento este tipo de literatura divulgou-se com o objetivo de inspirar para uma vida pia. As hagiografias constituíam o espelho e o modelo para uma vida sem vícios $^{14}$. Proliferava por toda a Espanha livros sobre S. Francisco Xavier, S. Francisco de Borja, Santa Teresa ${ }^{15}$. A "literatura de espelhos" sugeria padrões ideais de comportamento ${ }^{16}$. O arcebispo dá-nos como exemplo, no Estado da Índia, o papel de D. João III na reforma do reino, enviando para as suas Conquistas, "hum Santo Xavier, e otros varões Religiosos insignes em virtude, letras, e zello da Salvação das Almas"17. Noutra passagem menciona que São Francisco Xavier se queixara ao rei das "muitas injustiças" naquele Estado, pelo que podemos inferir que o livro sobre o dito santo, existente no catálogo, tinha sido alvo da sua leitura ${ }^{18}$.

Em suma, as narrativas hagiográficas foram importantes para concertar o novo arquétipo episcopal desenvolvido a partir de meados do século XVII.

${ }^{12}$ GOUVEIA, António Camões - "Dor e Amor em Frei Tomé de Jesus, Apontamentos para uma leitura e algumas interpretações". (Provas Públicas de passagem de Assistente Estagiário a Assistente, na F.C.S.H. da U.N.L., 1985), in Estudos em homenagem a João Francisco Marques, p. 45-64. (pdf).

${ }^{13}$ DIAS, José Sebastião da Silva - Correntes do sentimento religioso em Portugal (Séculos XVI a XVIII). Coimbra: Universidade de Coimbra, 1960, p. 322-323.

${ }^{14}$ HALICZER, Stephen - Between Exaltation and Infamy. New York: Oxford University Express, 2002, p. 29.

${ }^{15}$ Cf. Idem, p. 32.

${ }^{16}$ PAIVA, José Pedro - Os Bispos de Portugal e do Império. 1495-1777. Coimbra: Imprensa da Universidade de Coimbra, 2006, p. 139.

${ }^{17}$ DGARQ - Manuscrito Livraria 1816, fl. 39v.

${ }^{18}$ Cf. Idem. fl. 39v. 
O título Curso de Moral Salmaticense reunia uma recompilação da doutrina onde se estabeleciam os princípios sólidos da moral cristã e evangélica que auxiliava os confessores e diretores de consciência a obter "las reglas de la mas sana doctrina"19. O uso amiúde da confissão era um dos preceitos mais utilizados pelos jacobeus, o que exigia aos confessores um perfeito conhecimento daquele sacramento. Os bispos avaliavam e indicavam as obras auxiliares, de forma que manuais de confessores e catecismos tornar-se-iam um recurso precioso.

Os Verdaderos entretenimientos del glorioso Señor S. Francisco de Sales, o mesmo autor da Introdução à Vida Devota, apelava para a oração mental, ou seja, para o caminho da interiorização e diálogo com Deus, como a definia S. Gregório de Nissa "um colóquio e comunicação da alma com Deus", ou como Santo Agostinho e S. João Damasceno "um voo ou elevação do espírito para Deus"20. Esta prática da oração foi seguida por todos os defensores da oração mental, onde se inclui o arcebispo. Insere-se no pensamento místico, no sentido em que a oração era uma conversação secreta de coração para coração; como indicava S. Francisco de Sales é um "maná secreto porque se oculta à luz de qualquer ciência e na solidão mental" "21. Os Entretenimentos mostravam a forma de conduta a seguir pelos jovens e delineavam o carácter e o espírito que um bom sacerdote devia $\operatorname{adotar}^{22}$. Conclui-se que o humanismo devoto do santo terá tido grande influência na prédica do arcebispo.

A Mistica Cidade de Deus, de Sor Maria de Jesus Ágreda, encontra-se no rol. A carmelita foi objeto de raptos, visões e feitos maravilhosos, que criaram em torno dela uma religiosidade de prodígios ${ }^{23}$. Qual terá

${ }^{19}$ Compendio Moral Salmaticense Segun la Mente del Angélico Doctor en el quel se Reduce a Mayor Brevedad el que en lengua latina publicó el R. P. Frei Antonio de San Joseph, Lector y Prior que fue en el Colegio de Burgos, Exâminador Sinodal de este Arzobispado y Procurador general en la Curia Romana por la Congregacion, de los Carmeçlitas Descalzos de España, En Pamplona: En la Imprensa de Joseph de Rada, 1805.

${ }^{20}$ SALES, S. Francisco de - Tratado de amor de Deus / revista pelo Pe. Augusto Durão Alves, (3 ${ }^{\text {a }}$ edição). Porto: Livraria Apostolado da Imprensa, 1958, p. 246.

${ }^{21}$ Cf. Idem. p. 247.

${ }^{22}$ SALES, Saint François de - Les Entretiens, p.1. (http://www.abbaye-saint-benoit.ch/ bibliotheque.ht, consultado a 19/04/2011).

${ }^{23}$ ALCALÁ, Ángel y outros - Inquisición Española y Mentalidad Inquisitoria, Ponencias del Simposio Internacional sobre Inquisición. Barcelona: Editorial Ariel, S. A., 1984, 
sido a influência da sua obra na vida de D. frei Inácio de Santa Teresa? A sua piedade e visões sobre as conversões dos índios e em especial sobre A Vida da Virgem que acabara de escrever na época (1650) foram objeto de análise pela Inquisição de Logroño, porém, os ministros do Santo Ofício nada encontraram contra a fé ${ }^{24}$. $\mathrm{O}$ enfoque sobre a vida de Maria, de acordo com o testemunho da religiosa, revela os dados que lhe foram prescritos, em momentos de transe, pela própria Mãe de Jesus. Nela, a Virgem é transformada numa figura excelsa acompanhada, em atos da sua vida, por legiões de anjos e arcanjos, comandados por S. Miguel, a que se juntavam, por vezes, profetas e sacerdotes. É difícil avaliar o modo como os pensamentos de Sor Maria de Jesus Ágreda influenciaram o arcebispo, no entanto, as visões e o maravilhoso poderão tê-lo fascinado. Demonstra-se que foram objeto da sua análise nas Pérolas Orientais, dedicadas a D. João V, onde colocou as meditações místicas em texto, como se comprova no prólogo quando refere que não traduziu obra (como lhe haviam pedido) por achar que a língua castelhana era de fácil entendimento, daí "reduzir a vasta matéria daquella copioza, e celestial historia, a humas meditaçoens pias" ${ }^{25}$. Os reformadores místicos dos carmelitas, no século XVI, observavam os mesmos princípios orientadores da oração mental, do rosário, da leitura espiritual, da vida contemplativa e outros exercícios religiosos adotados pelo prelado que vivia uma vida austera de penitência e renúncia para fazer reparação de todos os pecados e implorar o perdão de Deus. É, pois, dentro deste panorama que se parte da possibilidade da carmelita ter tido um papel importante nas leituras do primaz de Goa.

Encontra-se na biblioteca, mas sem os títulos referenciados, o Mestre de Ávila, São João da Cruz, o que justifica que a produção e transmissão de literatura de espiritualidade começa a ter grande aceitação em Portugal, principalmente, entre os reformadores, daí entre os livros aparecer também o título, O Manual dos Padres Espirituais ${ }^{26}$. S. João da Cruz procurava a renovação da cristandade através da formação do clero baseada em

p. 434-460; Mistica Ciudad de Dios, (http://www.stjosephpublications.com/download/PDF/ cdd1.pdf, consultado em 20 de Março de 2014).

${ }^{24}$ ALCALÁ, Ángel e outros - Inquisición Española..., ob. cit., p. 444-445.

${ }^{25}$ DGARQ - Conselho Geral do Santo Oficio, Liv. 313, s/ numeração.

${ }^{26}$ TAVARES, Pedro - Beatas, Inquisidores e Teólogos..., cit., p. 3; p. 54-59. 
práticas pedagógicas humanistas e morais. Os seus escritos eram tratados fundamentais por apresentarem clareza e sabedoria clássica e cultivarem os valores de uma vida interior, virtuosa e asceta, procurando a perfeição espiritual e enfatizando o conhecimento próprio como caminho de união com Deus. Nos poemas apresentava uma grande dinâmica relacional com Deus/Cristo/Amado. Compreende-se que faça parte das escolhas do prelado.

Da biblioteca merece também atenção a obra Flores del Carmelo. A Primer Flor del Carmelo, de Pedro Calderón de La Barca, era um auto de representação, em poema de louvor a Maria, que utilizava figuras alegóricas para doutrinar. De um modo geral, seguia a temática religiosa como a vida dos patriarcas e figuras importantes do Antigo Testamento; os santos com seus milagres; o fim do mundo e o juízo final; mas o assunto mais recorrente era o das virtudes cristãs, sobre os sete pecados capitais ${ }^{27}$. Da Primer Flor del Carmelo, versos 317 a 334 pode avaliar-se a importância pedagógica do texto:
“(...)
ando discurriendo siempre
cómo vendrá, cuando venga,
el prometido Mesías,
que ahora sólo se deja
ver en figuras y sombras,
como son la escala de bella
de Jacob, la zarza viva
de Moisés, el haz de leña
de Isaac, el rocío cuajado
de Gedeón y la niebla
de Elías, sin otras muchas,
de quien hablan los profetas,
que en el seno de Abraham
depositados esperan,
en fe de Cristo venturo,
a que abra el cielo sus puertas"28.

${ }^{27}$ NEVES, Auricléa Oliveira das - La primer flor del Carmelo, um auto en louvor a María, p. 360-367.

${ }^{28}$ Caldéron de La Barca, Pedro - La primer flor del Carmelo, um auto em louvor a Maria, Biblioteca Virtual Universal, 71136, PDF, p. 10. 
A alusão a Jacob revela a importância da mística perpetuada pelo grupo denominado jacobeu, a entrada no céu subentendia a salvação das almas ${ }^{29}$.

Os Sermões do padre António Vieira faziam parte das duas bibliotecas, o gosto pela eloquência e a admiração pelo padre foi registado pelo arcebispo como "o nosso Cicero Portuguez, o grande Vieira" ${ }^{30}$. O jesuíta fora preso pela Inquisição, teve que defender-se da acusação que lhe fora imputada. Tendo o prelado enfrentado um problema semelhante é provável o gosto pelos sermões vieirinos. Poderá ser também uma das possíveis explicações sobre a existência de uma Apologia a favor do Padre António Vieira, de Soror Margarida Inácia, no rol de D. frei Inácio ${ }^{31}$. Na livraria de S. Inês existia a História do Futuro cujas ideias messiânicas e proféticas foram alvo do processo inquisitorial. A hermenêutica utilizada nesta obra tinha como principal objetivo a "conquista do mundo, seguida da conversão de outros povos e do estabelecimento da paz universal sob a égide da Igreja"32. Evocado muitas vezes nas pastorais pelo arcebispo, Vieira outorgaria o modelo da exegese bíblica literal, mística e alegórica com vista à formação moral ${ }^{33}$.

${ }^{29}$ PAIVA, José Pedro - Os Bispos de Portugal..., cit.; SILVA, António Pereira da (O.F.M.) - A questão do sigilismo em Portugal no século XVIII. História, religião e política nos reinados de D. João Ve de D. José I. Braga: Tip. Editorial Franciscana, 1964, p. 37-39; SOUZA, Evergton Sales - Jansénisme..., cit., p. 189-190; Ver também Epitome da vida do veneravel servo de Deos, Fr. Francisco da Annunciação, Mç. CIV/1-46 fl. 9v. e consultar ainda, os artigos de COSTA, Elisa Maria Lopes da - "A Jacobeia, achegas para a história de um movimento de reforma espiritual no Portugal setecentista", Arquipélago História, 2. " série, XIV-XV (2010-2011) 31-48; e "Nótulas para o estudo da Jacobeia", Bracara Augusta, vol. 43 (1992) 375-407; BLUTEAU, Raphael - Vocabulario Portuguez e Latino, Aulico, Anatomico, Architectonico, Bellico, Botanico, Brasilico, Comico, Critico, Chimico, Dogmatico. Coimbra: Collegio das Artes da Companhia de Iesu, 1712-1721, 8 vol., tomo I; SOTTO MAYOR in Conimbricense, $\mathrm{n}^{\circ}{ }^{\mathrm{o}} 2374$ de 24-4-1870, p. 1. ALMEIDA, Fortunato de - A História da Igreja em Portugal. Coimbra, 1915, tomo III, parte II, p. 766-795; MONCADA, Luís Cabral de "Mística e racionalismo em Portugal no século XVIII", Boletim da Faculdade de Direito, nº 28 (1952) 1-98; CASTRO, Zília Osório "Jacobeia" in AZEVEDO, Carlos Moreira (dir.) - Dicionário História Religiosa ..., cit., 2001, vol. 4, p. 5-10; SANTOS, Zulmira - "Luzes e Espiritualidades"..., cit., vol. II, p. 38.

${ }^{30}$ DGARQ - Manuscrito Livraria 1816..., cit., fl. 49.

${ }^{31}$ BNP - cod. 1524, fl. 294 e 294v; BGUC - cod. 1524, 293-293v.

32 BETHENCOURT, Francisco - “Tempos Humanos em Busca de Deus" in AZEVEDO, Carlos Moreira (dir.) - História Religiosa de Portugal, Lisboa: Círculo dos Leitores, 2000, vol. II, p. 86.

${ }^{33}$ MARQUES, João Francisco - "A Palavra e o Livro: Literatura de Espiritualidade” in AZEVEDO, Carlos Moreira (dir.) - História Religiosa I, p. 438. 
Não surpreende a plausível admiração pelo pregador que, por um lado, atraía os fiéis com a sua teatralidade e, por outro, era amado pelas elites.

Outro jesuíta focado pelo prelado foi o italiano Paolo Segneri (Pablo Señeri) que seguia a via da naturalidade para onde progredia a retórica moderna, empenhada em demonstrar a verdade e estigmatizar o erro $^{34}$. As três obras elencadas: o Mana da Alma, Cristãos Instruídos e Incrédulo auxiliariam a missão e a pregação que seriam, porventura, duas das maiores preocupações do prelado. O Mana da Alma seguia o discurso do medo, do temor do Inferno, mostrando assim, aos homens o perigo que corriam ${ }^{35}$. A prédica utilizada nas três obras visava essencialmente a formação do clero mas também contemplava o disciplinamento das consciências ${ }^{36}$. A obtenção da graça era essencial, faziam-se constantes apelos aos cristãos para se confessarem, o que se conjugava com a matriz dos jacobeus. O arcebispo utilizou o mesmo tipo de prédica: "Teme e acovarda-se o peccador ao entrar nos perigos, porque sabe, se o colher naquelle estado a morte, consequentemente o recolherá para sempre o Inferno... (...) ${ }^{n_{37}}$.

Dos livros consta o título: "De bem morrer" do jesuíta Estêvão de Castro. A obra leva-nos diretamente à confissão para a remissão dos pecados e preparação da morte, uma vez que era através dela que se obtinha a graça tão proclamada pelos jacobeus. O homem ia ao encontro de Deus através da penitência; era necessário que todos os sacerdotes fossem bem doutrinados para poderem praticar o terceiro sacramento. Zulmira Santos refere que Estêvão de Castro, em O Breve Aparelho e modo fácil para ajudar a bem morrer um cristão (1621), retoma tópicos dos manuais dos confessores mostrando a preocupação de uma boa confissão ${ }^{38}$. As pastorais e os escritos

${ }^{34}$ Cf. Idem, p. 438.

${ }^{35}$ SEGNERI, Paolo - Mana del Alma, O Exercicoi Fácil y Provechoso para Quien Desea Dar se de Algum Modo a la Oracion Propuesto por el M.R.P.Pablo Señeri, de la Compañia de Jesus. Madrid: Herederos de Antonio Romàn, Año de 1701, parte II, p. 4.

${ }^{36}$ Sobre o discurso do medo destacam-se as obras: DELUMEAU, Jean e MELCHIOR-BONET, Sabine-De religiões e de homens. São Paulo: Edições Loyola, 2000; DELUMEAU, Jean - Le Péché et la Peur, la culpabilisation en Occident XIII-XVIII siècles. Paris: Fayard, 1983; DELUMEAU, Jean e Monique Cottret - Le catholicisme entre Luther et Voltaire. Paris: P.U.F, 6. ${ }^{\text {a }}$ edição, 1996.

${ }^{37}$ DGARQ - Manuscrito Livraria 1816, fl. 86.

${ }^{38}$ SANTOS, Zulmira - "Entre a "Doutrina" e a Retórica: Os Tratados sobre os Quatro Novíssimos (1622) de Frei António Rosado O. P. in Os «Últimos Fins» na Cultura Ibérica (XV-XVIII), Revista Faculdade Letras - Linguas e Literaturas, Anexo VIII (1997) 161-172. 
do primaz de Goa refletem essa preocupação: "Receitem os confessores aos mayores pecadores do mundo, e submergidos, que estejão no peccado mais difficil da emenda, (...) meia hora, ou hum só quarto todos os dias de meditação, ou contemplação, e verão, mediante a Divina graça, effeitos della prodigiosos, e milagrosos" ${ }^{39}$. Espelhava deste modo, o cuidado com a prática da oração mental na absolvição dos pecados.

Achou-se por bem juntar, aos livros de índole espiritual, a Arte de ingenio, tratado de la agudeza de Lourenço Gracian, jesuíta, porque incidia sobre a dialética. No discurso $X X X X V$, De la Acolucia Y Trabaçón de los Discursos, Gracian escreveu que "el arte de hallarla sería el ultimo primor de la sutileza"40. Terá sido determinante como auxiliar na produção dos textos do arcebispo.

"Nova Floresta...", do padre Manuel Bernardes, foi usada pelo prelado ${ }^{41}$ :

“o Veneravel Padre Bernardes na sua Horesta, que perguntando, porque colhia sempre melhores, e mais copiozos fructos, que os outros, respondeo $=$ Porque tenho os tempos, como quero. E perguntando de novo, como podia isto ser, respondeo $2^{\mathrm{a}} \mathrm{vez}=$ Quero, o que Deos quer o que o mesmo dito Padre no mesmo lugar confirma com a auctoridade de Sto Agostinho= (...) Que o Reyno do Ceo padece força, e que só o conseguem, os que a fazem a si mesmos. Já sabem que pelo Reyno do Ceo, não só se torna no Evangelho a Igreja triumphante, que no Ceo reina gloriosa, mas tambem a Igreja militante, que na terra peleja laboriosa" ${ }^{\prime 4}$.

A obra seguia o programa do rigorismo jacobeu e a problemática da evangelização dos gentios pois focava a missão de S. Francisco Xavier. O padre Manuel Bernardes deixou tratados de espiritualidade e vários guias morais sobre o pecado ou a virtude ${ }^{43}$. É interessante perceber que a escolha literária de D. frei Inácio agregava todas as congregações e missões existentes em Goa. Conclui-se, portanto, que não havia arbitrariedade, nem lia somente os mentores da sua "escola", ou seja os textos procurados pelos

${ }^{39}$ DGARQ - Manuscrito Livraria 1816..., cit., fl. 63.

${ }^{40}$ GRACIAN, Lourenço - De Ingeno..., ob. cit., p. 1242. (Pdf)

${ }^{41}$ BERNARDES, Manuel - Nova floresta ou silva de vários apophtegmas e ditos sentenciosos espirituais e morais. Lisboa: Of. de Valentim da Costa Deslandes, 1706-1728.

${ }^{42}$ DGARQ - Manuscrito Livraria 1816..., cit., fl. 60 e 60v. Trecho do Título III, Da Alma

${ }^{43}$ Como se constata no Índice da obra: BERNARDES, Manuel - Nova floresta ..., cit. 
jacobeus. O arcebispo rodeou-se de todos os autores que lhe pudessem dar resposta a todas as missões existentes no Oriente.

As obras de Bartolomeu do Quental como as Meditações sobre a Vida de Cristo, que fazia parte do catálogo, tornaram-se provavelmente incontornáveis. A direcção para a oração mental de Quental harmonizava-se com as instruções escritas por Frei António das Chagas que recomendava a sua leitura. Também, o Directório para a oração mental, de Frei Manuel de Deus vai ter peso nos anos vinte do século XVIII ${ }^{44}$. A tendência para crer na corrupção integral da natureza humana, depois do pecado original, é marcante. O pessimismo antropológico aproximava-se das correntes jansenizantes ${ }^{45}$. O padre Bartolomeu de Quental, "pregador supernumerario" da Capela Real de D. João IV, e mais tarde nomeado confessor da casa real terá tido relevo na parenética do metropolitano de $\mathrm{Goa}^{46}$. No prólogo dos "Sermões" escreve o próprio padre Bartolomeu que os orienta para "práticas meramente espirituais (...) resumidas no fim de cada uma com pontos pera a meditação" ${ }^{47}$. Sabe-se que na biblioteca de Panchim e na de S. Inês existem diversos Sermões sem identificação; no entanto, a obra "Meditações" está catalogada. $\mathrm{O}$ oratoriano tornou essenciais as meditações e o exercício da oração mental, facto a que o arcebispo não era alheio. A metodologia persuasiva de Quental observa-se também nas atitudes adotadas por D. frei Inácio na sociedade goesa de cariz tão peculiar. O sistema de castas, estranho ao mundo ocidental, era permeável ao cristianismo, pois este dava uma resposta positiva, isto é, a conversão traria privilégios:

"somente he o receyo, de que convertendo-se huns e os outros não, os convertidos hão de ser excluidos da casta pelos remanescentes (...) Pelo que se houvesse hum meyo para se converterem todos juntos,

${ }^{44}$ TAVARES, Pedro - Beatas, Inquisidores e Teólogos ..., cit., p. 27; MARQUES, João Francisco - "A Palavra”..., cit., p. 397.

${ }^{45}$ MARQUES, João Francisco - "A Palavra”..., cit., p. 90.

${ }^{46}$ PIRES, Maria Lucília Gonçalves "O Padre Bartolomeu de Quental pregador da capela real”, Revista da Faculdade de Letras Série "Línguas e Literaturas", Anexo V, Porto, 1992, p. 155-170.

DGARQ - Chancelaria de D. João IV, Liv. 26, fl. 197v.

${ }^{47}$ Cf. Idem. p. 158. 
ou quaze, ou a mayor parte, sem duvida se conseguiria com facilidade este desejado fim" ${ }^{\prime 4}$.

Para além do problema da evangelização dos gentios havia ainda que modelar os comportamentos dos portugueses que se estabeleceram em Goa. A reforçar esta ideia está o documento escrito e intitulado pelo próprio arcebispo da seguinte forma: "Estado do Estado da Índia, meyos faceis e efficazes para o seu augmento e reforma espiritual e temporal. Tratado Politico, Moral, Juridico, Theologico, Historico e Ascético que teve principio Em dia da santissima Trindade, em que se canta o Evangelho. (...)"49.

D. frei Inácio terá comungado do discurso de Bartolomeu de Quental pois, este valorizava a oração mental como "fundamento de toda a reforma e perfeição da vida espiritual" ${ }^{50}$. As Meditações faziam parte dos livros escolhidos também por D. Miguel da Anunciação, outro jacobeu do círculo do arcebispo-bispo ${ }^{51}$.

Brados do seu pastor às suas ovelhas do franciscano D. Frei José de Santa Maria de Jesus, bispo de Cabo Verde, publicado em 1731, em Lisboa, torna-se o espelho do bispo missionário, preparava pedagogicamente o clero das missões ${ }^{52}$. A obra divide-se em duas partes "um conjunto de quarenta praticas, breves e claras para utilização dos párocos nos domingos e dias santos em que não houvesse sermão, bem como para o uso dos pais de família na instrução dos seus filhos, e hum Espelho de Dezengano para peccadores confiados" ${ }^{53}$. É provável que o arcebispo a tenha seguido ou, pelo menos, ela era uma referência para os párocos. O bispo de Cabo Verde tinha assumido o cargo na mesma época e ambos apreciavam as reformas do Varatojo. A obra realçava a pastoral do medo, focava vários delitos, entre eles, o da mancebia, que também foi um dos campos de batalha do prelado.

${ }^{48}$ DGARQ - Manuscrito Livraria 1816..., cit., fl. 6.

${ }^{49}$ Cf. Idem. fl. 1.

${ }^{50}$ GONÇALVES, Maria Lucília - "O padre Bartolomeu de Quental orador da capela real"..., cit., p. 162.

${ }^{51}$ MARQUES, João Francisco - “A Palavra”..., cit., p. 377-447.

52 TAVARES, Pedro - "Hora das Imagens da Morte na Pastoral Missionária, Os Brados do Bispo de Cabo Verde, D. Frei José de Santa Maria de Jesus (1731), Os «Últimos Fins» na Cultura Ibérica (séculos XVII-XVIII), Revista da Faculdade de Letras-Linguas e Literaturas, Anexo VIII, 1997, p. 237-255.

${ }^{53}$ Cf. Idem. p. 240. 
Segundo Pedro Tavares, Brados tinha como objetivo incitar à oração mental e fazer frequentes apelos à confissão ${ }^{54}$, valores que uniam os dois bispos sob a égide jacobeica.

As obras de índole espiritual eram leitura obrigatória como prescrevia a máxima $\mathrm{n}^{\circ}$ 18: "Apontem-se as coisas especiais que se acham nos livros espirituais". Esta vertente é visível na atuação de D. frei Inácio, pois ordenava que, nas freguesias e nos conventos, se fizesse "o Santo exercicio da meditação, ou oração mental publica, precedendo alguma lição espiritual" como tinha introduzido "com não pequeno fructo" 55 . Por conseguinte, os seus livros confirmam esta sua dimensão intelectual filiada a uma moral assente no rigorismo, na mística e na oração mental ligando-o ao círculo Granadino. Um dos problemas apontados aos jacobeus foi a possível ligação a Jansénio, que ia contra a filosofia exteriorista da prédica religiosa barroca, impondo uma relação intimista com Deus através da oração mental. O jansenismo era fortemente influenciado por uma "mística de raízes agostinianas e porventura calvinistas", o que fizera evidenciar o individualismo, acentuado já por si pela filosofia cartesiana ${ }^{56}$. Embora em Portugal não se tenham encontrado vestígios do jansenismo, Silva Dias foca que a jacobeia encontra em Jansénio e Port-Royal alguma similitude mas que em nada se pode interligar estas duas visões da Igreja portuguesa ${ }^{57}$. Tese que este estudo perfilha. D. frei Inácio de Santa Teresa foi acusado de ter proferido num sermão proposições próximas de Baio e de Jansénio. Apesar dessa acusação, o arcebispo não se aproximou dos ideais jansenistas e nada teve a temer, tendo sido isento de qualquer culpa.

Em que medida os manuais referidos terão servido como auxiliares nas questões tidas com os jesuítas, os franciscanos, os oratorianos?

O que se pode afirmar é que o arcebispo conhecia bem a escola que formava as referidas congregações e ordens. Possuía livros orientadores da sua vida religiosa oriundos de todos esses quadrantes. Porém, no meio trigo

${ }^{54}$ TAVARES, Pedro - "Hora das Imagens"..., cit., p. 251-253.

${ }^{55}$ DGARQ - Manuscrito Livraria 1816..., cit., fl. 52v.

${ }^{56}$ DIAS, J.S. Silva - Portugal e a Cultura Europeia (séculos XVI a XVIII). Separata de Biblos, Vol. XXVIII, Coimbra: Coimbra Editora, 1953, p. 99.

${ }^{57}$ DIAS, J.S. Silva - Portugal e a Cultura Europeia, (Séculos XVI a XVIII). Porto: Campo das Letras, 2006, p. 187-188. 
nasce o joio, ou seja, a ignorância por parte de alguns religiosos das missões, mais tentados pelos bens terrenos que pelos celestes, era controlada pelo metropolitano e está registada nas pastorais ou na correspondência trocada.

Por último, mas não de somenos, as Sagradas Escrituras eram parte integrante do arsenal catequético do arcebispo. Sobre a legislação do ordinário e a pregação escolheu no Antigo Testamento: o salmo dois (S1 2) que diz respeito às duas jurisdições, a temporal e a espiritual, e sobre os infiéis, no que considera à pregação da fé, "como assentão todos os escholasticos, e escripturisticos, com os Santos Padres". Do Pentateuco, nomeadamente no Levítico (Lv 20) procurou o que ajuíza sobre as punições aos cristãos. Uma das preferências mais pertinentes foi a que diz respeito ao Deuteronómio [Dt.I (Nm 25-1-15)] que foca a proibição de idolatria ${ }^{58}$.

Do Novo Testamento, surge com mais frequência nas pastorais $\mathrm{s}^{59}$ :

- O Evangelho segundo S. Lucas, por distinguir a singularidade do acontecimento salvífico de Jesus Cristo que poderia transformar a vida das pessoas com reflexo nos seus comportamentos sociais: "a Igreja, e o seo Pastor universal, como Vigario, e lugar tenente de Christo na terra, tem o mesmo jus, e poder para obrigar os infieis directe a ouvirem a pregaçam da Fé"60.

- As Cartas de S. Paulo aos Coríntios (realçam a luta contra os abusos da igreja e a forma de os remediar) ${ }^{61}$.

- O Evangelho de São João, designadamente o que remete para a confissão, Jo 20, “ (...) se collige o preceito divino da confissão, e o jus do poder a Igreja compellir a ella a todos os fieis".

- O Evangelho segundo São Mateus, Mt 17, explica o mistério messiânico e a transfiguração de Cristo $^{62}$.

No que diz respeito à conversão dos gentios, defendeu a importância do rei no auxílio ao prelado: "Sua Magestade pode e deve obrigar aos gentios seos vasallos a assistencia da doutrina", bem como "proibir os pagodes"63.

\footnotetext{
${ }^{58}$ Notas retiradas da Nova Bíblia dos Capuchinhos, para o terceiro milénio. Coimbra: Difusora Bíblica, 1998 (Coordenador geral: Herculano Alves, ofmcap).

${ }^{59}$ ALVES, Ana Ruas - “O Reyno de Deos"”..., cit., p. 96.

${ }^{60}$ DGARQ - Manuscrito Livraria 1816..., cit., fl. 10.

${ }^{61}$ Cf. Idem. fl. 10.

${ }^{62}$ Cf. Idem. fl. 12.

${ }^{63}$ Cf. Idem. fl. 7.
} 
Usou para sustentar a ideia o Novo Testamento (S. Lucas, S. João, S. Mateus e S. Paulo ${ }^{64}$ ) e o Antigo Testamento: "Livro 4 dos Reys lemos varios artigos, com que Deos opprimio, e ainda destruio os Israelitas pelos cultos de falsos Deoses, e falsa Religião, que admittirão, e introduzirão por conveniencias politicas" ${ }^{\circ 5}$. Imputava ao príncipe o dever de "constranger os infieis subditos a deixar erros, e ritos, que repugnão a ley natural, e que são contrarios a fé", com o Deuteronómio 13 e $17^{66}$.

D. frei Inácio escreveu sermões mas essa fonte, que poderia ser utilíssima para traçar o seu sentimento religioso, lamentavelmente não chegou até nós.

A biblioteca continha livros de direito Canónico, provavelmente, auxiliares no uso da aplicação e defesa da sua jurisdição ordinária. Um dos nomes de referência é Feliciano de Oliva e Sousa e o Tratado de Foro Eclesiástico. É muito provável que o arcebispo o tenha usado para se salvaguardar dos que se opunham à jurisdição: jesuítas, franciscanos, oratorianos, mónicas e o sufragâneo, bispo de Malaca. Este último punha em causa a jurisdição ordinária e a hierarquia institucional, o Tratado dava resposta a esta polémica, descrevia o tipo de relação jurídica entre um prelado inferior para com o seu superior ${ }^{67}$.

Em questões de poder temporal, o arcebispo fez uma reflexão que projeta a relação com o vice-rei; transcreve-se o que diz respeito aos costumes.

“ (...) o Canon Consuetudo dist. 8, que non $\operatorname{diz}=$ Consuetudo sine veritate vetustas erroris est, Propter quod, relicto errore, sequamur veritatem $=$. E o Canon Sana dist. 10, que diz $=$ Sana quippé ratio etiam exemplis anteponenda est $=\mathrm{E}$ hé certo que assim o pede a boa razão, que aos prelados nas suas igrejas se lhes dem as primeiras honras, como ordenão as leys eccleziasticas, e as ceremoniaes. E que tudo o que houver contra isto, ainda que seja estabelecido por ley e costume se reforme" ${ }^{68}$.

${ }^{64}$ Cf. Idem. fl. 11.

${ }^{65}$ CF. Idem. fl. $19 \mathrm{v}$.

${ }^{66}$ Cf. Idem. fl. 13.

${ }^{67}$ BGUC - Feliciano de Oliva e Sousa - Tratactus de Foro Ecclesiae. Conimbricae: Ex officina Emmanueli de Carvalho, Universitatis Thypographi, 1649-[1650], 2 vol., fls. 256v. Ver também ALVES, Ana Ruas - “O Reyno de Deos”..., cit., p. 122-162.

${ }^{68}$ DGARQ - Manuscrito Livraria 1816..., cit., fl. 34. 
Quanto ao poder espiritual, a relação com as várias missões e ao modo como aqueles agiam de má-fé, escreveu:

"Se os prelados na realidade prevaricarem, tem difficultoso remedio, mas hé necessario proceder no credito desta prevaricação, e das accusações, que com a madura, e ponderação recomendada nos sagrados Canones $=$ Nullam damnationem $=(\ldots)$ que não permitte ser nenhum Bispo condemando por menos de 72 testemunhas idoneas, e taes, que possão admittir por accusadores de hum Prelado"69.

No que diz respeito ao dever do príncipe em auxiliar o "bispo" na evangelização dos gentios, socorreu-se do cânone de Judaeis:

“ (...) donde a Igreja prohibe aquellas coacções à Fé, não por falta de poder, ou jurisdição nos Principes para com os subditos (pois no dito canon de Judaeis louva o zello de Sisebuto Rey, e ractifica semelhante coacção feita por elle, ainda que ordena, que dali por diante se não uze della) mas pellos inconvenientes, que se seguem do contrario" 70 .

Para sustentar as suas ideias, utilizou nas pastorais e nos registos pessoais nomes de canonistas como Pignateli, Soares, Gravanto, Arriaga, De Luca, entre outros.

O livro Decreta omnia a Sacra Rituum Congregatione, de Gravanto, provavelmente auxiliou-o a conviver com as missões e a estabelecer códigos de relacionamento entre ele e as diferentes congregações e ordens. ${ }^{71}$

Ao rol de livros religiosos e de direito canónico juntam-se outros que revelam o gosto abrangente do arcebispo pela história, literatura e poesia, como são a História Universal de Bossuet, a Crónica de El Rei D. Afonso Henriques de quem relata: "a Monarchia Luzitana teve seo solido, e estavel fundamento, e a sua gloriosa exaltação em dous Reys tão insígnes servos, e Protectores da Igreja, como forão o Santo Rey D. Afonço Henriques,

${ }^{69}$ Cf. Idem. fl. $35 \mathrm{v}$.

${ }^{70}$ Cf. Idem. fl. 8v.

${ }^{71}$ GAVANTO, Bartolomeo - Decreta omnia a Sacra Rituum Congregatione in Ordine ad Missam, post Missalis recognitionem: una cum observationibus, et Regulis selectis R.P.D.Bartholomaei Gavanti S. Rom. Rituum Congreg. Consultoris, perutilibus, ac necessariis, ut ritè semper celebratur: ad Laurentio Vander Hammen, \& Leon fideliter excerpta, \& in haec altera editione recognita, novisq [ue], \& permultis, indicatis insignita, \& locupletata. Ulyssippone: ex Officina Antonio Alvarez, 1635. 
e o fortunadissimo D. Manuel o $1^{\circ}$, fundando 150 templos"72. A Vida do Imperador Carlos $V$, a Peregrinação de Fernão Mendes Pinto e as Honras de Filipe IV. Na poesia distingue-se $A$ Fénix Renascida.

Em síntese, D. frei Inácio de Santa Teresa revelou-se um homem bem preparado, conhecedor das leis de que dispunha para governar o arcebispado. A experiência que vivenciara nos Cónegos Regrantes de Santo Agostinho, em Coimbra, provavelmente fizera dele um homem exigente com sólidos conhecimentos. O seu academismo possivelmente influenciou a praxis que seguiu na governação, para além do espírito atreito a uma vida beata assente no rigorismo jacobeu. A literatura piedosa reflete a constante renovação espiritual e as reformas pastorais.

\section{Conclusões}

As opções tomadas por D. Inácio de Santa Teresa ao longo da vida, o cruzamento do poder espiritual e do poder temporal, projetaram a sua prelazia no mundo setecentista dividido entre o regalismo, o racionalismo e um misticismo reparador das falências do Concílio de Trento, no século das Luzes. A cura da alma e a disciplina dos comportamentos estavam dependentes da competência do prelado, do seu perfil, da sua formação e das suas escolhas. A ação do clero que orientava era cuidadosamente analisada nas visitas e nas pastorais que redigia. Só com uma formação muito sólida e um paradigma rígido é que a sua governação se poderia impor num meio multirreligioso (hinduísta e islamita). A formação leva-nos às leituras e aos livros disponíveis para consulta e provável uso na administração e na parenética utilizada.

Assim, como diretor de consciências tinha algumas obras de referência: um homem conhece-se pelo que lê. Possuidor de uma biblioteca com 197 livros, que abarcavam temáticas diversificadas como direito canónico, teologia, hagiografias, história, matemática, medicina e poesia, revelam-nos que era um prelado culto e informado. Nas suas leituras destacam-se: Santo Agostinho, S. Tomás de Aquino, Santa Teresa de Ávila, frei Luís de

${ }^{72}$ DGARQ - Manuscrito Livraria 1816..., cit., fl 26. 
Granada, padre António Vieira, entre outros. Como arquétipo de homem culto e piedoso ligado ao misticismo revelava a preferência pelos círculos de Granada e de França. Misticismo que se inscrevia num processo de defesa e prática interior e na procura de uma harmonia possível entre a oração interior e o culto exterior desequilibradamente sobrevalorizado, dando à oração mental uma atenção especial ${ }^{73}$. As leituras e os títulos que o prelado distinguia fizeram dele um ótimo jurista canónico e, ao mesmo tempo, um teólogo astuto: as tramas em que o envolveram foram ultrapassadas em parte devido à sua formação académica.

Do seu discurso podemos concluir a intencionalidade de expressar o seu pensamento levando o clero e os fiéis a aderir à sua orientação religiosa Jacobeica, isto é, seguindo uma vida disciplinada e contemplativa com o recurso à oração mental, unindo assim, o seu saber ao seu poder eclesiástico assente no rigorismo e na conjugação salvífica do amor de Deus.

${ }^{73}$ GOUVEIA, António Camões - "Quietismo" in, AZEVEDO, Carlos Moreira (dir.) Dicionário de História Religiosa. Lisboa: Círculo dos Leitores. 2001, vol. 4. p. 87-90. 


\section{Anexo}

Tabela 1 - Lista de livros de D. frei Inácio de Santa Teresa em Panchim

\begin{tabular}{|l|c|}
\hline $\begin{array}{l}\text { Lista dos Livros proprios, que S. Ilustrissima deixa na Livraria } \\
\text { de Panchim }\end{array}$ & Tomos \\
\hline Pignateli toda a obra & 11 \\
\hline Berlinch. Theatrum vitae Humanae & 8 \\
\hline Delbene & 5 \\
\hline Politica de Bobadilha & 2 \\
\hline Rainaldo observasiones criminales & 4 \\
\hline Chronica de S. Francisco & 6 \\
\hline Curso Moral Salmaticense & 6 \\
\hline Ubertu decstationibus & 1 \\
\hline Oliva de foro Ecclesiae & 1 \\
\hline Mysthica Ciudad de Dios & 3 \\
\hline Expeditio Hispanica de Souza & 2 \\
\hline Flores del Carmelo, ou vidas de varios Santos Carmelitas & 1 \\
\hline Vida do padre José Anchieta & 1 \\
\hline Cardenas toda a obra & 1 \\
\hline Todo o dereito Canonico & 4 \\
\hline Figuero in Sacram Scrituram & 2 \\
\hline Rosignol Theologia, e dereito & 15 \\
\hline Corrad. Praxis dispensation & 2 \\
\hline Loter. De Re benificiaria & 2 \\
\hline Controversia sobre os Ritos Malabaricos do padre Brandolini & 3 \\
\hline Fenis renascida & 8 \\
\hline Escolla de corial & 7 \\
\hline Guerreiro de Recusatione & 4 \\
\hline Antonelo de Loco, et Tempore Legali & 2 \\
\hline Obras de Fr Luis de Granada & 2 \\
\hline Obras do Mestre Avila, fica em S. Ignes & 1 \\
\hline Bisso Decas moralis & 1 \\
\hline Summa de Diana & 1 \\
\hline Sá hum tomo in Sacram Scripturam & 1 \\
\hline Epitome de Suares Granatense & 1 \\
\hline Brecorio & 3 \\
\hline Tertulianus pradicans, & 2 \\
\hline Alguns Sermoens Italianos & 1 \\
\hline Rellaçoens varias & 1 \\
\hline Jardim Sagrado & 16 \\
\hline & \\
\hline
\end{tabular}


Tabela 2 - Lista de livros de D. frei Inácio de Santa Teresa em Santa Inês ${ }^{74}$

\begin{tabular}{|c|c|}
\hline $\begin{array}{c}\text { Lista dos Livros proprios, que S. Ilustrissima deixa na } \\
\text { Livraria de S. Ignes }\end{array}$ & Tomos \\
\hline Direito Canónico em fólio & 3 \\
\hline Direito civil & 3 \\
\hline Labata moral & 2 \\
\hline Consultas de Torrecilha & 7 \\
\hline Senéri Mana del Alma & 4 \\
\hline Senér i Christão instruidos & 4 \\
\hline Senéri Incredulo & 2 \\
\hline Senéri Misereré & 1 \\
\hline Bossuet Historia Universal & 2 \\
\hline Euzebio Nieremberg & 3 \\
\hline Apologia de Noboa & 1 \\
\hline História do Futuro do Vieira & 1 \\
\hline Meditações do padre Quental da Vida de Cristo & 2 \\
\hline Reseto Augustiniano & 1 \\
\hline Villacastim & 1 \\
\hline Chronica de El Rey Dom Afonso Henriques & 1 \\
\hline Obras do Mestre Avilla & 1 \\
\hline Vida do Imperador Carlos 5. ${ }^{\circ} 2 .^{\mathrm{a}}$ parte & 1 \\
\hline Paes incanticum Moyses & 1 \\
\hline Idem in Epistolam Jacob & 1 \\
\hline Philosophiae naturalis principia mathematica & 1 \\
\hline Mystica Ciudad de Dios & 1 \\
\hline Oliva de foro Ecclesiae 2. ${ }^{a}$ parte & 1 \\
\hline Suares de Gratia tomo $1 .^{\circ}$ & 1 \\
\hline Bernardes Militaciones dos Novissimos & 2 \\
\hline Idem ultimo fim & 1 \\
\hline Idem Nova Floresta & 5 \\
\hline Cerimoniale Episcoporum & 1 \\
\hline Concordantiae Bibliorum & 1 \\
\hline Biblia Sacra pequena & 1 \\
\hline Peregrinação de Fernão Mendes Pinto & 1 \\
\hline Anno Historico & 1 \\
\hline S. Francisco de Sales entretenimento & 1 \\
\hline Concilio Tridentino com as anotações de Barbosa & 1 \\
\hline Istoria de S. Anastasio & 1 \\
\hline Brados de Pastor do Bispo de Cabo Verde & 1 \\
\hline Manual de Padres Espirituaes 1 tomo em oitavo & 1 \\
\hline
\end{tabular}

${ }^{74}$ BGUC - cod. 1524, 293-293v. 


\begin{tabular}{|c|c|}
\hline $\begin{array}{c}\text { Lista dos Livros proprios, que S. Ilustrissima deixa na } \\
\text { Livraria de S. Ignes } \\
\end{array}$ & Tomos \\
\hline Apologia a favor do padre Antonio Vieira de Soror Margarida Ignacia & 1 \\
\hline Monarchia Lusitana cinco tomos pertencentes a Livraria de Panchym & 5 \\
\hline Decizoens da rota pertencentes a mesma & 1 \\
\hline Lus da Medicina & 1 \\
\hline Obras de Santo Augustinho & 1 \\
\hline Idem tomo $2 .^{\circ}$ & 1 \\
\hline Gavanto & 1 \\
\hline Gracian. Arte de Inguenio & 1 \\
\hline Sermoens de Vieira Primeira parte & 1 \\
\hline Torre de Babilonia de Antonio Henriques & 1 \\
\hline Honras de Philipe $4 .^{\circ}$ & 1 \\
\hline Castro [Estêvão] de Bem Morrer & 1 \\
\hline Ordenação do Reino, que pertence a Livraria de Panchy & 1 \\
\hline Total & 81 \\
\hline
\end{tabular}

